\title{
VIDEOJUEGOS Y APRENDIZAJE DE LA HISTORIA: LA SAGA ASSASIN'S CREED
}

\author{
Diego Téllez Alarcia \\ Diego Iturriaga Barco \\ Universidad de La Rioja
}

\begin{abstract}
RESUMEN: Este artículo estudia el potencial de los videojuegos en general y de la saga de Assasin's Creed en particular para el aprendizaje de la Historia. Para ello analiza las características de los videojuegos, su poder motivacional, sus tramas, los aspectos históricos que mejor ilustra y también sus limitaciones.
\end{abstract}

PALABRAS ClAVE: Historia, videojuegos, Assasin's Creed, aprendizaje significativo.

\section{VIDEOGAMES AND LEARNING OF HISTORY: THE ASSASIN'S CREED SAGA}

\begin{abstract}
This article studies the potential of videogames, in general, and Assasin's Creed saga, particularly in the learning of History. It analyzes the characteristics of videogames, their motivational power, its plots, the historical aspects that best illustrates and also its limitations.
\end{abstract}

KEYWORDS: History, videogames, Assasin's Creed, meaningful learning.

Recibido: 18/04/2013

Aceptado: 28/07/2013

\section{INTRODUCCIÓN: VIDEOJUEGOS Y APRENDIZAJE DE LA HISTORIA}

Todavía a día de hoy persisten numerosos prejuicios y estereotipos acerca del rol de los videojuegos en la vida de nuestros alumnos. Afortunadamente cada vez son más las voces autorizadas que defienden que este recurso posee un enorme potencial para generar aprendizajes de diversos tipos. Gee en su libro Lo que nos enseñan los videojuegos sobre el aprendizaje y el alfabetismo (Gee, 2004) Ilega a enumerar 36 principios o formas de aprender de un videojuego. Sin necesidad de listarlos todos, 
sí que merece la pena hacer mención de varias ventajas significativas frente a otros recursos habituales en la enseñanza de cualquier nivel:

1. Iniciación a un nuevo alfabetismo: en nuestra sociedad de la imagen y las nuevas tecnologías, el empleo de videojuegos suele significar en muchos casos todo un proceso iniciático a un nuevo lenguaje, a un "nuevo ámbito semiótico paralelo al de la letra impresa" (Gil y Vida, 2007: 86), lenguaje y ámbito en el que nuestra sociedad se basa cada vez más (Zagalo, 2010 y López, Encabo y Jerez, 2011).

2. Interactividad: la participación activa del jugador en el desarrollo de la historia tiene diversos efectos positivos. Por un lado resulta motivador, capturando la atención del usuario más que con cualquier otro medio pasivo (libro, fotografía, cine). Lo que resulta particularmente importante en un mundo cada vez más regido por el concepto de la "economía de la atención" (Goldhaber, 1997). Esta motivación convierte el aprendizaje en significativo. Por otro lado el proceso de aprendizaje que se establece en los videojuegos se basa en la vieja premisa del ensayo-error sin que este último sea castigado. Al contrario, es integrando y reflexionando sobre las equivocaciones como se avanza en la mayor parte de los videojuegos (Marín y García, 2005).

3. Desarrollo de habilidades: jugar desarrolla habilidades personales y emocionales (superación de retos, autoconfianza, expresión de sentimientos), sociales (interiorización de normas y comportamientos, cooperación, trabajo en equipo), psicomotoras (orientación espacial, coordinación viso-mano, rapidez, precisión) y cognitivas (curiosidad, percepción visual y auditiva, capacidad organizativa, toma de decisiones, solución de problemas, análisis) (Pindado, 2005).

Si se parafrasea a Andrew Miller todo docente puede llegar a hacerse la siguiente pregunta una vez diseccionadas debidamente estas ventajas: ¿deben los alumnos jugar videojuegos en clase? Su respuesta es clara: "nuestros estudiantes están jugando videojuegos, nos guste o no (...) en lugar de ver esto como una pérdida de tiempo, algunos educadores están viéndolo como una oportunidad y usando los juegos en clase" (Miller, 2012).

La enseñanza de la Historia no escapa a esta realidad (Ayen, 2011). Existe una enorme variedad de videojuegos susceptibles de ser utilizados por los docentes para generar aprendizajes significativos en sus alumnos: juegos de estrategia histórica como Age of Empires, Europa Universalis o Imperium (Ayen, 2009, 2010), títulos más comerciales como Tomb Raider o Prince of Persia, shooters como Medal of Honor o Call of Duty, juegos de rol online como World of Warcraft o Everquest, etc. El objetivo de este artículo es analizar una de las sagas de videojuegos "históricos" más exitosas de los últimos tiempos: Assassin's Creed y responder a preguntas básicas como: ¿Es posible realizar aprendizajes significativos a través de este recurso? ¿Qué se puede aprender con él? ¿Cuáles son sus principales virtudes y cuáles sus posibles limitaciones?

\section{Materiales y método: la saga Assassin's Creed}

Assassin's Creed ("El Credo de los Asesinos" AC en adelante) es una saga de videojuegos de acción ambientada en distintos episodios históricos y desarrollada por la compañía francesa Ubisoft, creadora de otras célebres series como Prince of Persia. AC se 
adscribe al género conocido como Acción/Aventura y se juega en tercera persona. Ahora bien, AC es particularmente conocido por haber incorporado a esta tipología de juego el concepto de open world, un tipo de diseño en el que el jugador puede interactuar con absoluta libertad en todo un mundo virtual creado por los programadores a tal efecto. También le caracteriza el hecho de ser un stealth game o juego de sigilo, en el cual la derrota de los rivales depende no tanto de la habilidad o de la fuerza bruta como del sigilo con el que se enfrenta a ellos. En palabras de K. Stuart una perfecta combinación de "exploración acrobática, intrincadas conspiraciones y combate audaz" (2010).

La fecha de lanzamiento del primer videojuego de la saga $(A C I)$ se remonta a noviembre de 2007, siendo octubre de 2013 la fecha de estreno del último (AC IV). Dado lo prolífico de esta serie se resume en la siguiente tabla los principales videojuegos, sus años de aparición y las plataformas en que pueden disfrutarse. Como puede comprobarse, se trata de un enorme conglomerado de videojuegos basados en una misma trama.

Para la elaboración de este estudio se han utilizado todos ellos. En la siguiente tabla aparecen listados, así como las plataformas donde pueden jugarse. Desde un punto de vista metodológico, cabe indicar que se ha realizado una exploración individual de cada entrega con el fin de examinar su potencial educativo para el campo de la Historia, extrayendo la información que proporciona (épocas en que está ambientada, personajes históricos y ciudades que se utilizan, etc.). Una vez obtenidos estos datos se ha realizado una síntesis de los rasgos comunes a toda la saga para realizar una valoración final de sus virtudes y sus defectos y concluir si su potencial educativo es elevado o no. Todo ello, alimentado y sostenido con el debido apoyo bibliográfico.

Tabla 1. Todos los juegos de la saga Assasin's Creed y las plataformas en las que pueden jugarse

\begin{tabular}{|c|c|c|c|c|c|c|c|c|c|c|c|c|c|c|c|c|}
\hline \multirow{3}{*}{ Año } & \multirow{3}{*}{ Juego } & \multicolumn{15}{|c|}{$\begin{array}{r}\text { Plataformas } \\
\end{array}$} \\
\hline & & \multicolumn{3}{|c|}{ Consolas } & \multicolumn{2}{|c|}{\begin{tabular}{|l|} 
Ordenadores \\
\end{tabular}} & \multicolumn{3}{|c|}{ Consolas portátiles } & \multicolumn{5}{|c|}{ Móviles } & \multicolumn{2}{|c|}{ Otros } \\
\hline & & PS3 & $\times 360$ & Wii & Mac & Win & $\begin{array}{l}\text { DS/ } \\
\text { 3DS }\end{array}$ & PSP & Vita & And & iOs & Symb & webOS & WP & Face & OnLive \\
\hline \multicolumn{17}{|c|}{ Assassin's Creed - Tercera Cruzada } \\
\hline 2007 & $A C$ & Sí & Sí & No & No & Sí & No & No & No & Sí & No & No & No & No & No & No \\
\hline 2008 & $\begin{array}{l}\text { AC Altaï's } \\
\text { Chronicles }\end{array}$ & No & No & No & No & No & Sí & No & No & No & Sí & Sí & Sí & Sí & No & No \\
\hline 2009 & AC Bloodlines & No & No & No & No & No & No & Sí & No & No & No & No & No & No & No & No \\
\hline \multicolumn{17}{|c|}{ Assassin's Creed II - Renacimiento } \\
\hline 2009 & $A C \|$ & Sí & Sí & No & Sí & Sí & No & No & No & No & No & Sí & No & No & No & Sí \\
\hline 2009 & $\begin{array}{c}\text { AC II } \\
\text { Discovery }\end{array}$ & No & No & No & No & No & Sí & No & No & No & Sí & No & No & No & No & No \\
\hline 2010 & $\begin{array}{c}\text { AC Project } \\
\text { Legacy }\end{array}$ & No & No & No & No & No & No & No & No & No & No & No & No & No & Sí & No \\
\hline 2010 & $\begin{array}{c}A C \\
\text { Brotherhood }\end{array}$ & Sí & Sí & No & Sí & Sí & No & No & No & No & No & Sí & No & No & No & Sí \\
\hline 2011 & AC Revelations & Sí & Sí & No & No & Sí & No & No & No & Sí & No & Sí & No & No & No & Sí \\
\hline 2012 & \begin{tabular}{|c|}
$A C$ \\
Recollection
\end{tabular} & No & No & No & No & No & No & No & No & No & Sí & No & No & No & No & No \\
\hline
\end{tabular}


Tabla 1. Todos los juegos de la saga Assasin's Creed y las plataformas en las que pueden jugarse (continuación)

\begin{tabular}{|c|c|c|c|c|c|c|c|c|c|c|c|c|c|c|c|c|}
\hline \multirow{3}{*}{ Año } & \multirow{3}{*}{ Juego } & \multicolumn{15}{|c|}{ Plataformas } \\
\hline & & \multicolumn{3}{|c|}{ Consolas } & \multicolumn{2}{|c|}{ Ordenadores } & \multicolumn{3}{|c|}{ Consolas portátiles } & \multicolumn{5}{|c|}{ Móviles } & \multicolumn{2}{|c|}{ Otros } \\
\hline & & PS3 & $X 360$ & Wii & Mac & Win & $\begin{array}{l}\text { DS/ } \\
\text { 3DS }\end{array}$ & PSP & Vita & And & iOS & Symb & webOS & WP & Face & OnLive \\
\hline 2012 & $\begin{array}{c}\text { AC: } \\
\text { Multiplayer } \\
\text { Rearmed }\end{array}$ & No & No & No & No & No & No & No & No & No & Sí & No & No & No & No & No \\
\hline \multicolumn{17}{|c|}{ Assassin's Creed III - Revolución Americana } \\
\hline 2012 & $A C I I I$ & Sí & Sí & Sí & No & Sí & No & No & No & No & No & Sí & No & No & No & No \\
\hline 2012 & $\begin{array}{c}\text { AC III } \\
\text { Liberation }\end{array}$ & No & No & No & No & No & No & No & Sí & No & No & No & No & No & No & No \\
\hline 2013 & $\begin{array}{l}\text { Assassin's } \\
\text { Creed IV: } \\
\text { Black Flag }\end{array}$ & Sí & Sí & Sí & No & Sí & No & No & No & No & No & No & No & No & No & No \\
\hline 2013 & $\begin{array}{c}\text { Assassin's } \\
\text { Creed: } \\
\text { Utopia }\end{array}$ & No & No & No & No & No & No & No & No & Sí & Sí & No & No & No & No & No \\
\hline 2013 & $\begin{array}{c}\text { Assassin's } \\
\text { Creed: } \\
\text { Pirates }\end{array}$ & No & No & No & No & No & No & No & No & Sí & Sí & No & No & No & No & No \\
\hline
\end{tabular}

Fuente: Wikipedia.

\section{ResUlTADOS: APRENDER HISTORIA CON AC}

AC comienza con la historia de Desmond Miles, un camarero descendiente de varias generaciones de miembros de la secta de los Hassasins (asesinos) que, pese a haber abandonado su estilo de vida es secuestrado por miembros de la multinacional Abstergo. Esta empresa oculta a los archienemigos de sus antepasados, los caballeros templarios. Asesinos y templarios llevan enfrentándose durante un milenio por el control de la humanidad y el secuestro de Desmond solo es un episodio más de esa lucha. Empleando una especie de máquina del tiempo capaz de bucear en las "memorias genéticas" de Desmond (el Animus), el jugador es Ilevado a tiempos pasados de la mano de los ancestros del asesino capturado. En los distintos videojuegos desarrollados de la colección, Desmond se reencarna en tres antepasados diferentes: Altair ibn-La'Ahad, un asesino sirio que vive en la época de la Tercera Cruzada; Ezio Auditore da Firenze, un noble italiano del Renacimiento; Connor, un asesino de origen Mohawk que colabora con los revolucionarios americanos durante la Guerra de la Independencia; y Eduard Kenway, un pirata de comienzos del siglo XVIII. El objetivo de todos ellos es localizar artefactos para componer un artilugio conocido como Edén, que permitirá la salvación de la humanidad. O su destrucción.

Todas las entregas se ambientan en una época histórica concreta y, dentro de ella, la acción tiene lugar en diversas ciudades representativas de dicho periodo. En la siguiente tabla se indican tanto la cronología como los personajes históricos y las urbes recreados en cada una de ellas: 
Tabla 2. Épocas, personajes históricos y ciudades recreadas en cada entrega de AC

\begin{tabular}{|c|c|c|c|c|}
\hline Entrega & Periodo & Años & Personajes históricos & Ciudades/Regiones \\
\hline$A C$ & $\begin{array}{l}\text { Tercera } \\
\text { cruzada }\end{array}$ & 1191 & $\begin{array}{l}\text { Al Mualim, líder Hassassins } \\
\text { Ricardo Corazón de León } \\
\text { Roberto de Sablé, templario } \\
\text { Garnier de Nablús, hospitalario } \\
\text { Guillermo de Monferrato } \\
\text { Ibn Jubayr, cartógrafo andalusí } \\
\text { Ibn Shaddad, biógrafo de Saladino }\end{array}$ & $\begin{array}{l}\text { Masyaf } \\
\text { Jerusalén } \\
\text { Damasco } \\
\text { Acre }\end{array}$ \\
\hline $\mathrm{ACII}$ & Renacimiento & 1499 & $\begin{array}{l}\text { Leonardo Davinci } \\
\text { Nicolás Maquiavelo } \\
\text { Catalina Sforza } \\
\text { Lorenzo de Medici } \\
\text { Papa Alejandro VI }\end{array}$ & $\begin{array}{l}\text { Venecia } \\
\text { Florencia } \\
\text { Roma } \\
\text { Forli } \\
\text { San Gimignano }\end{array}$ \\
\hline $\begin{array}{c}\mathrm{AC} \\
\mathrm{BRO}\end{array}$ & Renacimiento & 1499 & $\begin{array}{l}\text { Leonardo Davinci } \\
\text { Nicolás Maquiavelo } \\
\text { César Borgia } \\
\text { Lucrecia Borgia } \\
\text { Alejandro VI }\end{array}$ & $\begin{array}{l}\text { Roma } \\
\text { Nápoles } \\
\text { Navarra }\end{array}$ \\
\hline AC REV & Renacimiento & 1511 & $\begin{array}{l}\text { Piri Reis } \\
\text { Solimán el Magnífico } \\
\text { Príncipe Ahmet }\end{array}$ & $\begin{array}{l}\text { Estambul } \\
\text { Capadocia }\end{array}$ \\
\hline ACIII & $\begin{array}{l}\text { Revolución } \\
\text { americana }\end{array}$ & 1753-83 & $\begin{array}{l}\text { Charles Lee } \\
\text { George Washington } \\
\text { Thomas Jefferson } \\
\text { Samuel Adams }\end{array}$ & $\begin{array}{l}\text { Boston } \\
\text { Nueva York } \\
\text { Filadelfia } \\
\text { Zona fronteriza } \\
\text { Lexington } \\
\text { Concordia } \\
\text { Charlestown } \\
\text { Mar Caribe }\end{array}$ \\
\hline $\mathrm{AC} B L O$ & Cruzadas & 1192 & Armand Bouchart & Chipre \\
\hline AC DIS & Renacimiento & 1490 & $\begin{array}{l}\text { Cristóbal Colón } \\
\text { Torquemada } \\
\text { Luis Santángel } \\
\text { Isabel la Católica } \\
\end{array}$ & $\begin{array}{l}\text { Zaragoza } \\
\text { Barcelona } \\
\text { Granada }\end{array}$ \\
\hline AC IV & Siglo XVIII & 1717 & $\begin{array}{l}\text { Barbanegra } \\
\text { Jack "Calicó" Rackham } \\
\text { Benjamin Hornigold }\end{array}$ & $\begin{array}{l}\text { La Habana } \\
\text { Kingston } \\
\text { Nassau }\end{array}$ \\
\hline
\end{tabular}

Fuente: Elaboración propia.

El recorrido, tanto a nivel cronológico como geográfico, es impresionante. Una de las bondades de $A C$ radica precisamente en esta amplitud. Por si fuera poco, los desarrolladores de $A C$ tienen como una de sus prioridades la precisión de los escenarios donde transcurre la acción en cuya fisonomía se profundiza desde varias perspectivas perfectamente aprovechables para el aprendizaje de la historia como disciplina:

1. Perspectiva arquitectónica: los diseñadores ponen especial atención en que los edificios de cada urbe sean históricamente verídicos. Los principales hitos monumentales (landmark) de cada una de ellas son interpretaciones muy realistas 
de réplicas exactas de los edificios históricos en el momento del desarrollo de la trama. También la arquitectura menos conocida, la civil o la militar, es adecuada a los materiales, técnicas y soportes de cada momento histórico, dando una sensación de realismo imposible de obtener mediante ningún otro medio. Nos hallamos ante una reconstrucción virtual del entorno físico con un grado de realismo no alcanzado antes.

2. Perspectiva social: la investigación de los equipos de guionistas de $A C$ también trasladan las estructuras sociales de cada uno de los momentos históricos retratados a los videojuegos. Así, en la época de las cruzadas vemos claramente la separación entre los estamentos privilegiados, nobleza y clero, frente al estado Ilano, donde también apreciamos distintos grupos como artesanos, labradores, comerciantes...

3. Perspectiva política: aunque la trama de la saga obliga a retorcer muchos de los elementos y personajes políticos, su mera presencia como protagonistas de un videojuego tan cautivador promueve la curiosidad del jugador a posteriori. Ricardo Corazón de León, Leonardo da Vinci, los Borgia, Maquiavelo, George Washington, el pirata Barbanegra... No se trata, con todo, tan solo de personajes: fenómenos como las Cruzadas, el Renacimiento, la Revolución Americana, la época de los Descubrimientos, la piratería del Caribe; imperios como el británico o el español en América; o instituciones como los Templarios o la Santa Inquisición se dan cita en las tramas de las distintas entregas de $A C$.

4. Perspectiva de la cultura material y la tecnología: el vestuario, la alimentación, el armamento, los medios de transporte... ningún elemento de la cultura material y de la tecnología de las distintas épocas queda al azar. Si bien los diseñadores se toman tantas licencias "literarias" como precisan, el grueso del diseño del arte de los videojuegos posee una fidelidad más que notable perfectamente comparable a la de las mejores series de televisión o largometrajes.

5. Perspectiva geográfica: el manejo de mapas de las ciudades y de los territorios que recorren los protagonistas permite el desarrollo de habilidades procedimentales relacionadas con estos recursos. También hay partes de los juegos que transcurren en escenarios menos antropizados, lo que da a los usuarios la posibilidad de contemplar paisajes naturales con todos sus elementos físicos (relieve, clima, hidrología, vegetación, fauna) sin estar tan condicionados por la presencia del ser humano, aprendiendo también, en consecuencias, cuestiones de esta rama del conocimiento de las Ciencias Sociales tan interconectada con la Historia.

Toro Sánchez y Muñoz Bandera (2012: 693) sintetizan perfectamente todo lo anterior:

Reproducen ciudades históricas de las que existen visiones aéreas y panorámicas, que dependen de la consecución de los retos que se plantean en el juego. Destaca en especial por la fidelidad con la que se caracterizan los elementos arquitectónicos y edificios de gran representatividad (iglesias, catedrales, sobre todo de funciones religiosas, pero también edificios de tipo civil, como circos, anfiteatros, termas, etc., dependiendo de la ciudad en la que se encuentre el protagonista). Existen elementos, relevantes en 
el desarrollo del juego, que definen la identidad de los lugares, más allá de los puramente paisajísticos (productos artesanales, tradiciones, costumbres, etc.). Se distinguen estratos sociales, entre los que destacarían, los de tipo gremial. Ciertas misiones del protagonista transcurren en entornos menos antropizados, pudiéndose observar formaciones vegetales, rasgos topográficos e incluso geomorfológicos, que van cambiando a medida que avanza el protagonista. El uso de planos de ciudades que son decisivos en los objetivos del juego.

\section{Discusión: defectos en el potencial educativo de $A C$}

No todo son bondades en la saga AC. Es fácilmente asumible por cualquier educador que un videojuego sea capaz de motivar. Ahora bien: ¿trasmite los conocimientos adecuadamente? Dos son las críticas principales que se le pueden hacer a $A C$ en esta línea. La primera es la ausencia de organización en la trasmisión de los contenidos. Este desorden podría quizás generar aprendizajes inconexos que dificulten la futura incorporación de conocimientos. Sin embargo, lo cierto es que en la sociedad en la que vivimos la información se trasmite de un modo similar a través de los mass media, Internet, redes sociales, por lo que se atenúa levemente la importancia de la crítica. También se puede aducir a este defecto que se estimula al jugador a establecer por sí mismo una organización de contenidos, lo que es un aprendizaje valioso en sí mismo.

Por otro lado, la gran crítica que se le hace a $A C$ es la de su inexactitud. El punto de partida es devastador: los guionistas retuercen los datos que ofrece la historia para sus propios fines sin el menor escrúpulo. La orden templaria es convertida por arte de magia en una sociedad secreta que ha pervivido por siglos y que persigue controlar a la humanidad. Son los villanos. La manipulación no se queda ahí: una secta de asesinos de origen ismaelita, los Nizaríes o Hassassin, es elevada como contrapoder benéfico a los templarios. Desde esta simple estructura de equilibrio maniqueo, se derivan toda suerte de ficciones pseudo-históricas cuyo único fin es añadir tensión narrativa al videojuego: personajes, batallas, acontecimientos de relevancia de cada uno de los periodos de ambientación son utilizados sin pudor y adulterados cuando las circunstancias lo exigen para dar el dinamismo apropiado a las entregas.

Lejos de ser disimulada, esta actitud es abiertamente reconocida por los propios guionistas de cada uno de los $A C$. $A C$ no es un videojuego diseñado con fines educativos, sino un monstruoso producto comercial en el que la Historia, como en muchas películas u obras literarias, sirve de trasfondo y escenario. Ni más ni menos. ¿Desvirtúa esto el valor pedagógico de $A C$ ?

En absoluto. Y por varios motivos. Para empezar la ambientación no queda invalidada por las licencias literarias que se toman los guionistas como sucede en cualquier película, serie de televisión, cómic u obra literaria. Sigue siendo un recurso perfectamente válido para el aprendizaje significativo de muchas cosas. Máxime si se tiene en cuenta que el propio $A C$ incorpora información escrita fiable de cada uno de los personajes, monumentos e hitos en los distintos perfiles de los protagonistas. Pero más allá de esto existe un curioso efecto colateral de la falta de fidelidad a la historia por parte de la saga: la polémica y el debate que genera en sus seguidores. $A C$ es una de las familias de videojuegos que ha suscitado una mayor discusión en torno a su veracidad histórica y a su valor educativo en la red y en los medios de comunicación. 
Hay cientos de foros dedicados a descubrir sus imprecisiones. Este furor proviene, sin duda, de la sagacidad con que los ideólogos del videojuego mezclan en precisas dosis historia y ficción. También de sus inteligentes campañas de marketing. Alimentando el fenómeno viral con noticias, entrevistas a los desarrolladores, posts, blogs, tuits, etc. AC ha logrado aglutinar legiones de seguidores sedientos no solo de jugar sino, más importante para los educadores, de debatir. Y lo hacen apasionadamente. Sobre cada uno de los detalles del juego. El efecto es demoledor: "aunque educar no es su objetivo, al crear un escenario realista, $A C$ ha producido efectivamente un grupo de jugadores autodidactas" (Meyers, 2011). El jugador medio de AC no sólo aprende historia jugando al videojuego, sino también leyendo, investigando y discutiendo con otros jugadores sobre las verdades y las mentiras de su vehículo de entretenimiento.

En el caso de los responsables de la saga no se trata tanto de alcanzar una réplica exacta de cada periodo histórico sino de dar sensación de verosimilitud. En este sentido es totalmente cierto que Ubisoft invierte gran cantidad de tiempo, dinero y esfuerzo para lograr su propósito. Para ello los equipos de arte, diseño gráfico y los guionistas Ilevan a cabo investigación a gran escala, como describe Raphael Lacoste, director de la sección de arte:

No tenemos ni fotografías ni referencias contemporáneas con las que empezar cuando comenzamos a concebir un proyecto. Para lograr nuestros objetivos, nos comprometemos en largos e intensos periodos de investigación empleando documentación histórica, mapas de época, ilustraciones, cuadros, diarios de viaje, etc. También tenemos la suerte de poder viajar a las locaciones para tener un sentido real de las vistas, los sonidos y los olores de esas ciudades fascinantes" (Venables, 2011).

Un buen ejemplo es la reconstrucción de Roma en AC Brotherhood. Frischer y Stinso (2007) destacan la labor realizada por los diseñadores del juego al utilizar no solo los restos actuales de monumentos y ruinas de la época, tales como el Foro, el Coliseo o el Castillo de Sant'Angelo, sino también información de corte documental y arqueológica recopilada de la bibliografía disponible. En esta misma secuela el director de arte, Maxime Pelletier, aseguraba haber usado no solo textos históricos y artísticos como inspiración, sino también un intenso trabajo de campo viajando a Italia para embeberse de la cultura local. La propia simulación de la ciudad desde un punto de vista urbanístico está basada en un modelo informático generado con el mapa de Roma de Leonardo Bufalini de 1551 como base (Griffin, 2010).

En AC III, por su lado, parte de la investigación tuvo mucho que ver con la manera de hablar el idioma en la época, incluyendo el habla coloquial y los insultos. Para hacer más creíble el sonido de las ciudades americanas donde tiene lugar la acción se examinaron los distintos acentos y dialectos de la época: "De hecho estudiamos los datos del censo de población civil de Boston en aquella época. Así supimos que había una cierta cantidad de ingleses, escoceses, galeses, irlandeses y holandeses, y tratamos de mezclar a todos ellos en el audio" (Bonthuys, 2012).

Son tan solo algunos ejemplos ilustrativos pero dan buena idea de la capacidad de la franquicia de poner recursos y talento al servicio de la verosimilitud, como piedra angular de un proyecto que, en ningún caso, renuncia a la ficción para enganchar a sus seguidores. 


\section{Conclusiones}

El éxito comercial de la serie $A C$ ha sido sobrecogedor. $A C$ I y $A C$ // han vendido ambos más de 8 millones de copias. AC Brotherhood ha sobrepasado las 6'5 millones. En 2011 solo estas tres secuelas llevaban más de 28 millones de copias vendidas en todo el mundo. Si se suman todas sus entregas, la cifra supera los 38 millones. Estas cifras aplastantes tienen su correlato lógico en la opinión de los usuarios y, muy especialmente, de la crítica, que define $A C$ como "la serie más notoria en esta generación de consolas" (Favelevic, 2012).

Al reconocimiento del público y de la crítica, ¿debería unirse también el de los educadores? Ésta es la principal cuestión a discutir. Por un lado es cierto que $A C$ ha logrado lo que muchos profesionales de la historia no: que personas de toda procedencia geográfica y extracción social se interesen y logren aprendizajes significativos en el campo de la Historia. Que debatan sobre ella. Que se diviertan aprendiéndola. No en vano el espíritu de la saga se ceñiría bien a la idea de Gee de que "la teoría del aprendizaje humano incorporada a los buenos videojuegos" supera incluso a "las teorías del aprendizaje planteadas por la ciencia cognitiva" (Gee, 2004: 8-9).

Por otro, la recreación de las atmósferas de cada escenario, las arquitecturas, los sonidos, los objetos, las relaciones sociales y económicas, el armamento... la experiencia de jugar cualquiera de las secuelas es intensa. Fascinante. Difícilmente alcanzable con ningún otro recurso didáctico, sean cuadros de época, grabados, mapas, descripciones de viajeros, textos históricos o, incluso visitas in situ de los restos arqueológicos y monumentos disponibles. La capacidad de cautivar que tienen estas reconstrucciones supera a la más fina tecnología de modelado en 3D o a los efectos especiales del cine no sólo por su calidad sino, sobre todo, porque el alumno-jugador es parte activa de la trama, y no un simple consumidor pasivo.

A pesar de todo, como videojuego comercial que es, $A C$ posee limitaciones evidentes como la oferta de una serie de conocimientos desestructurados y, en ocasiones, poco profundos, o la carencia de exactitud histórica plena. Éste es sin duda uno de sus principales defectos. Pero también una de sus virtudes desde la óptica de la adicción: su capacidad para generar verosimilitud haciendo creíbles los escenarios pese a tramas, en ocasiones, disparatadas, engancha al usuario como ningún otro recurso es capaz de hacerlo. Quizás merece la pena correr el riesgo de generar aprendizajes erróneos, como sucede por otra parte con el cine o la literatura (la novela histórica, sin ir más lejos), ya que permite abrir un espacio de debate, investigación y confirmación de datos después de cada sesión de juego. La existencia de numerosos blogs y foros de discusión con este fin es clara prueba de ello. No es menos interesante la perspectiva de diseccionar el por qué de determinados errores o de determinadas ideas vertidas más o menos subliminalmente en cada entrega. Al fin y al cabo, como cualquier manifestación cultural de una sociedad, la industria de los videojuegos también depende de seres humanos con sus ideologías o intencionalidades ocultas. Antes o después habrá que pensar en investigarla como se hace con el cine en corrientes historiográficas tan interesantes como la Cinematic Contextual History.

En suma, parece razonable otorgar a este recurso un reconocimiento elevado por parte de la comunidad educativa, apoyándonos en el análisis de las características de cada una de sus entregas, de su capacidad motivacional y de su potencial formativo. 


\section{REFERENCIAS BIBLIOGRÁFICAS}

AYEN, F. (2009). Juegos de estrategia histórica (Mensaje en un blog). Disponible en: http://www.profesorfrancisco.es/2009/11/juegos-de-estrategia-historica.html.

AYEN, F. (2010). Aprender Historia con el juego Age of Empires. Proyecto Clío, 36. Disponible en: http://clio.rediris.es/n36/otros/Aprender_historia_con_el_juego_ Age_of_Empires.pdf.

AYEN, F. (2011). Los videojuegos en la didáctica de la Historia. Bits. Revista de la Asociación Espiral, Educación y Tecnología, 18. Disponible en: http://ciberespiral. org/bits/18/videojuegos-didactica-historia/.

BONTHUYS, D. (4 de octubre de 2012). Assassin's Creed 3 will be a history lesson (Mensaje en un blog). Disponible en: http://www.lazygamer.net/xbox-360/ assassins-creed-3-will-be-a-history-lesson/.

FAVELEVIC, I. (2012). Assasin's Creed 3 Review: New World, old problems. Blast Magazine, 10/11/2012. Disponible en: http://blastmagazine.com/the-magazine/ gaming/reviews/assassins-creed-3-review-new-world-old-problems/.

FRISCHER, B. y STINSON, P. (2007). The importance of scientific authentication and a formal visual language in Virtual Models of Archaeological sites. En Interpreting the Past: Heritage, New Technologies and Local Development. Brussels: Flemish Heritage Institute.

GEE, P. (2004). Lo que nos enseñan los videojuegos sobre el aprendizaje y el alfabetismo. Málaga: Aljibe.

GIL JUÁREZ, A. y VIDA MOMBIELA, T. (2007). Los videojuegos. Barcelona: Editorial UOC, 2007.

GOlDhABER, M. (1997). The Attention Economy and the Net. First Monday, 4. Disponible en: http://firstmonday.org/htbin/cgiwrap/bin/ojs/index.php/fm/article/ view/519/440.

GRIFFIN, J. (11 de noviembre de 2010). Rebuilding Rome for a game. The Irish Times. Disponible en: http://www.irishtimes.com/newspaper/ features/2010/1122/1224283825811.html.

LÓPEZ, A.; ENCABO, E. y JEREZ, I. (2011). Competencia digital y literacidad: nuevos formatos narrativos en el videojuego Dragon Age: Orígenes. Comunicar, 36, pp. 165-171.

MARÍN DÍAZ, V. y GARCÍA FERNÁNDEZ, Ma D. (2005). Los videojuegos y su capacidad didáctico-formativa. Pixel-Bit. Revista de medios y educación, 26, pp. 113-119.

MEYERS, K. (2011). Lessons from Assassin's Creed for Constructing Educational Games. Play The Past, 25/10/2011. Disponible en: http://www.playthepast. $\operatorname{org} / \mathrm{p}=2077$.

MILLER, A. K. (12 de noviembre de 2012). Should kids play games in the classroom (Mensaje en un blog). http://www.educationnation.com/index. cfm?objectid=9EC27B06-2C69-11E2-A3EB000C296BA163.

PINDADO, J. (2005). Las posibilidades educativas de los videojuegos. Una revisión de los estudios más significativos. Pixel-Bit. Revista de medios y Educación, 26, pp. 55-67. 
STUART, K. (19 de noviembre de 2010). Assassin's Creed and the appropriation of history (Mensaje en un blog). Disponible en: http://www.guardian.co.uk/ technology/gamesblog/2010/nov/19/assassin-s-creeed-brotherhood-history.

TORO SÁNCHEZ, F. J. y MUÑOZ BANDERA, J. F. (2012). Los videojuegos como recurso para la Didáctica de la Geografía. En Miguel González, R. de, Lázaro y Torres, M. L. de y Marrón Gaite, M. J. (Eds.), La educación geográfica digital (691693). Zaragoza: Universidad de Zaragoza.

VENABLES, M. (11 de marzo de 2011). Exclusive Interview: Ubisoft's Creative Teams on Assassin's Creed Revelations (Mensaje en un blog). Disponible en: http://www. wired.com/geekdad/2011/11/exclusive-interview-ubisofts-creative-teams-onassassins-creed-revelations/.

ZAGALO, N. (2010). Creative Game Literacy. A Study of Interactive Media Based on Film Literacy Experience. Comunicar, 35, pp. 61-67. 
